A bezoar is a tightly packed mass of undigested material that can be found anywhere within the gastrointestinal tract, from the esophagus to the rectum. Bezoars are most commonly found in the stomach but they occasionally form in the colon [1]. We report a 37-year-old man with what appeared to be a colonic mass but which was in fact a bezoar in the transverse colon that had been caused by watermelon.

A 37-year-old man was admitted to our hospital with a 1-year history of constipation. He had no history of chronic illness, surgery, or chronic drug usage. The results of physical and laboratory examinations were within normal limits. Colonoscopy was performed after 5 days of bowel preparation which comprised a clear liquid diet and oral sodium phosphate. A large mass was detected in the transverse colon (Figure 1). While the endoscopist was planning a forceps biopsy of the mass, a watermelon seed was noticed on the near surface of the mass and normal mucosa was seen underneath the movable lesion (Figure 2). On questioning, the patient reported that he had eaten a large watermelon 1 day before as part of his preparatory liquid diet. His constipation resolved with medical treatment.

Phytobezoars, which are composed of vegetable matter, are the most common type of bezoars. There have been some reports in the literature of phytobezoars causing intestinal obstruction, but colonic obstruction is rare $[2,3]$. In our patient the transverse colon was partially obstructed; the vegetable bezoar was not hard, and it was found to be mobile when pushed by the colonoscope. If we had not seen the

\title{
Vegetable bezoar simulating a malignant mass in the colon
}

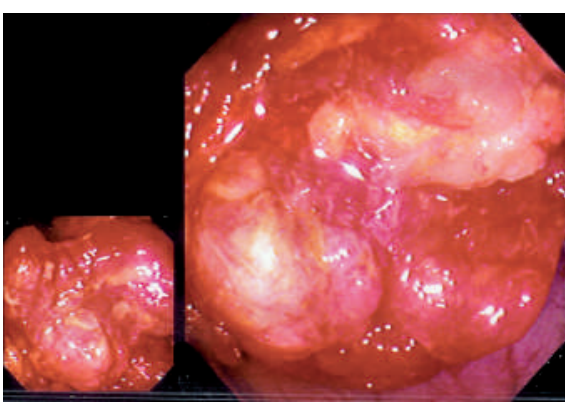

Figure 1 Colonoscopy revealed a suspiciouslooking mass in the transverse colon.

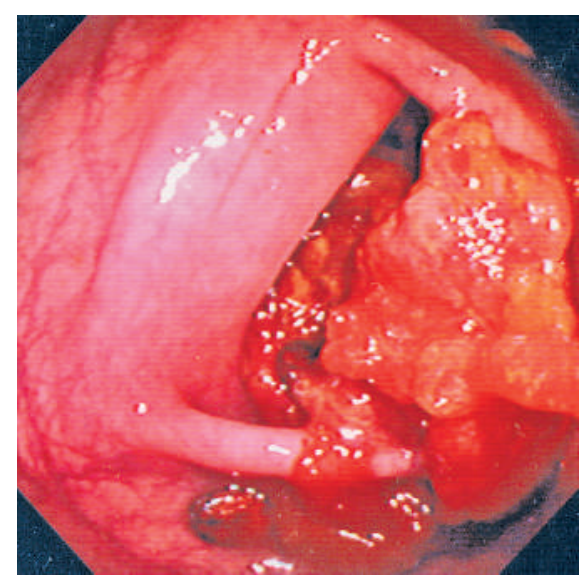

Figure 2 A watermelon seed was noticed on the near surface of the mass and normal mucosa was seen underneath the movable lesion.

watermelon seed or the normal-appearing mucosa under the suspicious mass and if we have not questioned the patient about the diet he undertook in preparation for the colonoscopic procedure, we would have taken a colonoscopic biopsy needlessly, which would have been a waste of resources.

Endoscopy_UCTN_Code_CCL_1AD_2AC
N. Akyurek Savas', U. Yilmaz', E.Ozaslan²

${ }^{1}$ Department of Gastroenterology, Baskent University Faculty of Medicine, Ankara, Turkey

2 Department of Gastroenterology, Ankara Numune Training and Research Hospital, Ankara, Turkey.

\section{References}

${ }^{1}$ Lafountain J. Could your patient's bowel obstruction be a bezoar? Todays Surg Nurse 1992; 21: $34-37$

${ }^{2}$ Larson J, Vender R, Camuto P et al. Phytobezoar of pure vegetable matter causing colonic obstruction. J Clin Gastroenterol 1995; 20: $176-177$

${ }^{3}$ Agha FP, Nostrant TT, Fiddian-Green RG. Giant colonic bezoar: a medication bezoar due to psyllium seed husks. Am J Gastroenterol 1984; 79: 319-321

\section{Corresponding author}

\section{N. Akyurek Savas, M.D.}

Department of Gastroenterology

Baskent University Hospital

Fevzi Cakmak Cad. 10. Sok.

No: 45 Bahcelievler

Ankara 06490

Turkey

Fax: $\quad+90-312-2238665$

E-mail: nakyurek2000@yahoo.com 